18 years and under, offering them quality time to address risk behaviour, sexual activity, detection, treatment and prevention of sexually transmitted infections (STI's). The legal age of consent in Ireland is 17 years, however many attendees are under this age or report prior sexual activity under the age of consent. As a result healthcare providers often find themselves operating in a legislative vacuum. This prospective study, performed between January and April 2012 examines presentations to the YPC, including age of coitarche, number of partners, prevalence of STI's and satifaction of parents.

Results A total of 110 patients attended the YPC, 71\% (N78) female, $29 \%(\mathrm{~N}=32)$ male. Clinical details were analysed. $45 \%$ $(\mathrm{N}=50)$ were asymptomatic. A total of $98 \%$ (N108) underwent HIV testing of whom were HIV negative. $16.36 \%(\mathrm{~N}=18)$ were diagnosed with Chlamydia Trachomatis, $17 \%(\mathrm{~N}=19)$ with Genital Warts, 3.6\% $(\mathrm{N}=4)$ with primary Herpes Simples.

$18 \%(\mathrm{~N}=20)$ had sex for the first time at 14 years of age, $5.5 \%$ $(\mathrm{N}=6)$ admitted to having had at least 20 partners.

A total of $30 \%(\mathrm{~N}=33)$ were unaccompanied. Of those accompanied $31.1 \%(\mathrm{~N}=24)$ were accompanied by mother, $5.1 \%(\mathrm{~N}=4)$ father, $16.8 \%(\mathrm{~N}=13)$ careworker and other relatives $5.1 \%(\mathrm{~N}=4)$. The remaining $49.1 \%(\mathrm{~N}=55)$ by either partner or friends.

A total of 45 parent satisfaction surveys were completed. While $6 \%(\mathrm{~N}=3)$ expressed concerns about their child attending the service without their knowledge, overall they were very impressed and $100 \%$ stated they would recommend the service to others.

Conclusion This study demonstrates that within our YPC cohort there was a high prevalence of sexual activity below the age of consent. With several having multiple partners, risky sexual behaviours and consequently a wide spectrum of STI's

\section{P2.161 EXPLORING THE ACCEPTABILITY OF ONLINE STI TESTING FOR RURAL YOUNG PEOPLE IN VICTORIA}

doi:10.1136/sextrans-2013-051184.0425

IJ E Tomnay, ${ }^{2} \mathrm{~L}$ Bourke, ${ }^{3} \mathrm{C}$ K Fairley. ${ }^{C}$ Centre for Excellence in Rural Sexual Health, The Univerisity of Melbourne, Shepparton, Australia; ${ }^{2}$ Rural Health Academic Centre, The Univerisity of Melbourne, Shepparton, Australia; ${ }^{3}$ Melbourne Sexual Health Centre, Melbourne School of Population and Global Health. The University of Melbourne, Australia

Background Rural young people living in Australia experience disadvantage in service access for STI testing and treatment. As such, innovative programmes using telemedicine have been developed but results show relatively low usage. Websites offering free online STI testing address issues of access; however acceptability of these services to rural young people is unknown.

Method Participants were recruited from small country towns in Victoria and grouped by gender and age. During focus groups participants were asked to discuss their access to local sexual health services (what services they used, when, why and how) and then shown a website and asked to provide feedback about online STI testing

Results Fifty participants from two small rural towns in Victoria were interviewed via seven focus groups. Both towns have GP services but no specialist sexual health services. Six main themes emerged in relation to acceptability of online STI testing. These were (1) readiness to seek sexual health services (2) credibility of the website, (3) using the mail during online STI testing, (4) getting the test results, (5) cost of the online service and (6) using the local GP versus using online testing. The participants identified a number of factors that may influence the use online services including the availability and acceptability of existing local services and whether the website looks credible, is confidential and free. In general the participants described some concerns about accessing sexual health services locally. This was less discussion about availability of services and more about privacy, trust, reliability and using generalist health care providers for sexual health needs.
Conclusion Free online testing services address issues of access for rural young people. While barriers external to rural sexual health services may remain, free online STI testing services are acceptable to these rural young people.

\section{P2.162 HEALTH-RELATED QUALITY OF LIFE AND BIOLOGICAL TEST RESULTS AS PREDICTORS OF ADVERSE ADOLESCENT PELVIC INFLAMMATORY DISEASE OUTCOMES}

doi:10.1136/sextrans-2013-051184.0426

'M E Trent, ${ }^{2} \mathrm{R}$ B Ness, ${ }^{3} \mathrm{D}$ Bass, ${ }^{3} \mathrm{C}$ L Haggerty. ${ }^{1} J o h n s$ Hopkins School of Medicine, Baltimore, MD, United States; '2 University of Texas School of Public Health, Houston, TX United States; ${ }^{3}$ University of Pittsburgh Graduate School of Public Health, Pittsburgh, $P A$, United States

Background Adolescents who experience pelvic inflammatory disease (PID) are highly likely to experience adverse reproductive health outcomes. Some adolescents might benefit from intensive clinical services to prevent recurrent disease and/or associated sequelae such as chronic pelvic pain (CPP). The objective of this study is to explore the relationship between health-related quality of life (HROL) and baseline biological outcomes with subsequent reproductive health outcomes.

Methods We conducted secondary analysis of longitudinal data from the 386 young women $\leq 21$ years of age enrolled in the Pelvic Inflammatory Disease Clinical Evaluation and Health (PEACH) Trial. Demographic and reproductive health histories, SF-12 HROL assessments, and biological samples for sexually transmitted infection (STI) testing (Chlamydia trachomatis (CT) and Neisseria gonorrhoeae (GC)) were provided at baseline and follow-up research visits. Stepwise linear regression analyses were conducted to assess differences in HROL over time, baseline HROL and reproductive health outcomes, and baseline STI status and 32-month HROL outcomes.

Results There were significant improvements in mean physical health $(\mathrm{PH})$ and mental health $(\mathrm{MH}) \mathrm{HROL}$ scores from 5-days to 32 months (PH: 61.7 vs. 79.4, MH: 58.3 vs. 68.6, p<0. 001). While the 5-day HROL was not predictive of CPP at 32 months, women who had recurrent STI/PID over 32 months had lower 5-day mental health composite and physical functioning subscale scores. Women with non-GC/CT PID at baseline had lower 32-month HROL composite scores for physical and mental functioning than those with GC/CT positivity at baseline.

Conclusions Lower baseline HROL scores are associated with recurrent STI/PID and non-GC/CT PID is associated with lower $\mathrm{HROL}$ at 32 months. Additional work exploring the potential use of baseline biological STI outcomes and HROL to enhance risk delineation during service delivery for vulnerable young women with mildmoderate PID is warranted.

\section{P2.163 DO "IN-CLINIC" MOLECULAR AND NON-MOLECULAR RAPID TESTS IMPROVE PATIENT MANAGEMENT?}

doi:10.1136/sextrans-2013-051184.0427

${ }^{1}$ E M Harding-Esch, ${ }^{2} \mathrm{~A}$ Hegazi, ${ }^{2} \mathrm{O}$ Okolo, ${ }^{3} \mathrm{M}$ J Pond, ${ }^{2} \mathrm{~A}$ V Nori, ${ }^{1} \mathrm{~A}$ Nardone, ${ }^{4} \mathrm{P}$ Baraitser, ${ }^{5} \mathrm{~L}$ Campbell, ${ }^{2} \mathrm{P}$ Hay, ${ }^{3} \mathrm{~S}$ T Sadiq. ${ }^{1}$ Health Protection Agency, London, UK; ${ }^{2}$ Courtyard Clinic, St George's Healthcare NHS Trust, London, UK; ${ }^{3}$ St George's University of London, Centre for Infection \& Immunity, Division of Clinical Sciences, London, UK; ${ }^{4}$ Camberwell Sexual Health Centre, King's College Hospital NHS Foundation Trust, London, UK; ${ }^{5}$ Academic department HIVIGUM, Guy's, King's and St Thomas' School of Medicine Weston Education Centre, London, UK

Background Excluding HIV testing, point-of-care tests (POCTs) for STIs are not routinely available in UK sexual health clinics, apart from microscopy which has limited sensitivity, is observer dependent and often only allows for imprecise syndromic treatment. From sample-to-result for routine Chlamydia trachomatis (CT) and Neisseria gonorrhoeae (NG) molecular tests usually takes several 
days. Molecular and non-molecular STI-POCTs, including automated urine flow cytometry, may improve patient pathways, obviate the need for microscopy and personalise treatment effectively. Methods This was a clinic evaluation using a rapid molecular test for CT/NG (Cepheid GeneXpert; 90 minute turnaround) combined with non-molecular POCTs for Trichomonas vaginalis (OSOM), Bacterial vaginosis (Alere VS-Sense) and automated urinary white cell count (WCC) for urethritis (Alere UF-100). Contacts of CT/NG, males with symptoms of urethritis, and symptomatic females provided samples immediately on arrival, prior to clinical consultation. Patients also concurrently had routine culture and microscopy. Results

\section{Abstract P2.163 Table 1}

\begin{tabular}{|c|c|c|c|}
\hline & Males & Females & Total \\
\hline Number of patients recruited & 19 & 39 & 58 \\
\hline Cepheid CT positive: N (\% of total) & $5(26.3)$ & $0(0)$ & $5(8.6)$ \\
\hline Cepheid NG positive: N (\% of total) & $1(5.3)$ & $0(0)$ & $1(1.7)$ \\
\hline Non-gonococcal urethritis by smear: $\mathrm{N}$ (\% of male total) & $9^{a}(47.4)$ & $\mathrm{N} / \mathrm{A}$ & $9^{a}(47.4)$ \\
\hline $\begin{array}{l}\text { Non-gonococcal urethritis by automated urine white } \\
\text { cell count } N \text { (\% of male total) }\end{array}$ & $8^{a}(42.1)$ & $\mathrm{N} / \mathrm{A}$ & $8^{a}(42.1)$ \\
\hline OSOM TV positive: $\mathrm{N}$ (\% of female total) & $\mathrm{N} / \mathrm{A}$ & $4^{\mathrm{b}}(10.3)$ & $4^{b}(10.3)$ \\
\hline Microscopy TV positive: $\mathrm{N}$ (\% of female total) & $\mathrm{N} / \mathrm{A}$ & $2^{\mathrm{b}}(5.1)$ & $2^{b}(5.1)$ \\
\hline Alere BV positive: $\mathrm{N}$ (\% of female total) & $\mathrm{N} / \mathrm{A}$ & $24(61.5)$ & $24(61.5)$ \\
\hline Microscopy BV positive: N (\% of female total) & $\mathrm{N} / \mathrm{A}$ & $7^{\mathrm{b}, \mathrm{c}}(17.9)$ & $7^{\mathrm{b}, \mathrm{c}}(17.9)$ \\
\hline Waited for CT/NG test result: N (\% of total) & $3(15.8)$ & $12(30.8)$ & $15(25.9)$ \\
\hline
\end{tabular}

a Urethral smear and WCC not done for 2 patients; Urethral smear alone was not done for 1 patient and the result was unavailable for 4 patients

${ }^{\mathrm{b}}$ Microscopy was not done for 4 patients; 1 of these was positive for both the TV and BV POCTs

${ }^{\mathrm{C}}$ An additional 9 were borderline

Of eighteen patients providing feedback, all but one found providing samples on arrival acceptable; waiting $<2$ hours was acceptable to all, but waiting $>2$ hours was seen as too long. All patients waited for the results of their non-molecular POCT but only three of nineteen men waited for the rapid GeneXpert results, despite six being positive. All positive patients were given appropriate empirical treatment. A third of women waited despite all being GeneXpert negative. The TV and BV POCTs detected more cases than microscopy, and urethral smear detected more urethritis than automated WCC.

Conclusion Despite the provision of genital samples on arrival being acceptable and patients liking the idea of receiving results in the same clinical visit, only a quarter of all patients waited for their GeneXpert results. Larger studies to evaluate the clinical impact of rapid molecular testing in clinic are required before any large scale implementation is considered.

\section{P2.164 HIGH STI RATES IN A NURSE DELIVERED OUTREACH SERVICE FOR SEX WORKERS-SWISH CLINIC}

doi:10.1136/sextrans-2013-051184.0428

${ }^{1} \mathbf{R}$ Turner, ${ }^{2} \mathrm{M}$ Campbell, ' $\mathrm{S}$ Day, ${ }^{1} \mathrm{~A}$ Sullivan. ${ }^{\top}$ Chelsea and Westminster Hospital NHS Foundation Trust, London, UK; ${ }^{2}$ Terrence Higgins Trust, London, UK

Background Sex Workers into Sexual Health; the SWISH service, was established to meet the specific needs of individuals who sell sex but may not attend mainstream sexual health clinics. It is run in collaboration with the Terrence Higgins Trust, and moved to a new location in January 2012 within an NHS Primary Care practise. SWISH is run as a walk in service though individuals can also book appointments. The aim of this study was to determine the rates of sexually transmitted infections amongst individuals attending SWISH.
Methods Notes review of clients accessing the SWISH clinic between $1^{\text {st }}$ January and $31^{\text {st }}$ December 2012.

Results Ninety-six patients attended SWISH during the study period; 58 were male (60\%), 25 were female (26\%) and 13 were transgender females (14\%). The overall STI prevalence was $23 \%$ (Table)

Rates of sexually transmitted infections by gender:

\section{Abstract P2.164 Table 1}

\begin{tabular}{lllllll}
\hline & & & & & Genital \\
& $\begin{array}{l}\text { Chlamydia } \\
\mathbf{n}(\%)\end{array}$ & $\begin{array}{l}\text { Gonorrhoea } \\
\mathbf{n}(\%)\end{array}$ & $\begin{array}{l}\text { HIV } \\
\mathbf{n}(\%)\end{array}$ & $\begin{array}{l}\text { HSV } \\
\mathbf{n}(\%)\end{array}$ & $\begin{array}{l}\text { warts } \\
\mathbf{n}(\%)\end{array}$ & $\begin{array}{l}\text { Total } \\
\mathbf{n}(\%)\end{array}$ \\
\hline Total, $\mathrm{n}=96$ & $8(8.3)$ & $4(4.2)$ & $2(2.1)$ & $5(5.2)$ & $3(3.1)$ & $22(22.9)$ \\
Male, $\mathrm{n}=58$ & $7(12.1)$ & $2(3.4)$ & $2(3.4)$ & $4(6.9)$ & $1(1.7)$ & $16(27.6)$ \\
Female, $\mathrm{n}=25$ & - & - & - & $1(4)$ & $1(4)$ & $2(8.0)$ \\
Transgender female, & $1(7.7)$ & $2(15.4)$ & - & - & $1(7.7)$ & $4(30.8)$ \\
$\mathrm{n}=13$ & & & & & & \\
\hline
\end{tabular}

Discussion This study highlights the significant prevalence of sexually transmitted infections amongst patients who sell sex. The findings show the need to continue targeting sex workers in the community to encourage regular screening. The significantly higher rates in men and transgender female warrants further investigation, especially in relation to risk taking behaviours and associated factors.

\section{P2.165 10 YEARS OF EXPERIENCE: COMPREHENSIVE SEXUAL HEALTH SERVICES FOR FEMALE SEX WORKERS (FSW) IN COLOGNE}

doi:10.1136/sextrans-2013-051184.0429

${ }^{1,2}$ H Nitschke, ' ${ }^{1}$ Oliveira. ${ }^{1}$ Public Health Office, Köln, Germany; ${ }^{2}$ German STI Society (DSTIG), Bochum, Germany

Background The introduction of the new infectious diseases act in 2000 in Germany abolished compulsory STI-screening of FSW. Since then, the public health office in Cologne has been offering a comprehensive sexual health service for people without access to the regular health care system. Services are provided anonymously and free of charge and are complemented by outreach activities in female sex work venues. The staff is multi-professional and multilingual. We analysed client data to prove effectiveness and range of services.

Methods Since 2002 socio-demographic and clinical data of all clients visiting the counselling and medical services have been inserted in an Access data base. Data of all FSW who used the medical facilities between 2002 and 2012 were analysed using Epilnfo Software. Results Between 2002 and 2012, 2217 FSW with 83 different nationalities were attended, with a mean of 355 persons per year. Mean age at first consultation was 27.5 years. The percentage of FSW of non-German origin rose from $65 \%$ to $87 \%$. In $2002,36 \%$ of migrant woman came from Central Europe, in $201272 \%$. Per year, $48 \%$ of the patients seen were new, only $12 \%$ used the facilities for more than 5 years. In 2002, 41\% had no health insurance, whereas $75 \%$ in 2012 . The proportion of sexworkers tested positive was $12.6 \%$ for chlamydia infection, $4.3 \%$ for gonorrhoea, $0.9 \%$ for syphilis, and $4.3 \%$ for trichomoniasis. In $8.5 \%$ of FSW, a PAP smear IIID or higher was found. 5 FSW were newly diagnosed with HIV, 3 women were HIV-positive before first contact. At least once, 238 FSW were attended because of a pregnancy.

Conclusions User-friendly non-compulsory sexual health services are used by FSW considered hard-to-reach. Fluctuation is high and sexual health needs go far beyond STI-screening. Comprehensive gynaecological attention and outreach prevention as well as language skills are crucial. 